\title{
Fuentes de la Presidencia del Gobierno, para la historia de la presencia española en Africa del Norte, custodiadas en el Archivo General de la Administración del Estado en Alcalá de Henares
}

\author{
Ignacio Ruiz Alcaín \\ Director del Archivo Central del Ministerio de Relaciones con las Cortes \\ y de la Secretaría del Gobierno
}

Dada la complejidad de la estructura político-administrativa en que se plasmó la Acción de España en el Norte de Africa desde la segunda década del siglo actual hasta sus promedios —cuando dicha Acción vuelve a encauzarse por las vías exclusivamente diplomáticas por las que discurriera en un principio-, la presente ponencia se plantea como prioritario un objetivo: facilitar al investigador una vía de acceso clara al ingente depósito documental que, como lógico correlato de tal complejidad, se custodia en la hasta hace poco Sección de Africa, aunque también en alguna otra Sección del Archivo General de la Administración del Estado en Alcalá de Henares.

Y una primera constatación que, sin duda, colmará de satisfacción a los estudiosos o interesados en el tema: la de la que la documentación conservada en esa institución de archivos por las Administración española no se circunscribe a la etapa en que tal Acción africanista conjuga una triple vertiente diplomática, militar y, al fin, sin rebozo claramente administrativa y de gobierno; sino también a sus primeros balbucesos contempo- 
ráneos, allá por 1750, en que la Diplomacia sienta las bases de la expansión colonial.

Preocupación nunca desmentida del Ejecutivo español fue que aquella Acción se diese con caracterres de unidad, concentración y coordinación. Así lo vemos corroborado por el hecho de que cuando alcanza un determinado estadio de maduración, su dirección se centralice en un solo órgano administrativo, adscrito a la Presidencia del gobierno, no vacilándose en sustraer el Departamento especializado en la acción diplomática —el Ministerio de Estado- la práctica totalidad de sus competencias en este terreno (1).

$\mathrm{Y}$, recalquémoslo, al hablar de Marrueco, no nos estamos refiriendo aquí, cuando nos hacemos eco de esta aspiración a la unidad de acción gubernamental, sólo a la Zona de directo interés para el proyecto colonial hispano - el Protectorado-; sino también a una esfera que, desde los parámetros de la Realpolitik de la época, se consideró de legítima influencia española, la de Tánger (a la espera de que las alternativas militares de la Segunda Guerra Mundial hiciesen perder sitio en el tablero internacional a alguno de los competidores y permitiesen su incorporación lisa y llana, aunque momentánea, al Protectorado); o a aquellas plazas que como Ceuta y Melilla se estimaron siempre de soberanía por ser la presencia española en ellas bastante anterior al proyecto colonial decimonónico.

En este sentido, el Decreto de 5-I-1993 (Vid. Apéndice II) asignaba explícitamente la Acción de España en la Zona de Tánger a la Presidencia del Consejo de Ministros, llegando incluso hasta subordinar jerárquicamente al Cónsul General en la ciudad al Alto Comisario de España en Marruecos, si bien este último extremo fuera corregido por el posterior Decreto de 5-XI-1933.

Por lo que respecta a las plazas de soberanía, resultan significativos el R. D.-Ley de 31-X-1927 atribuyendo la Gobernación general de tales plazas al Alto comisario; el R. D. de 10-IV-1930 asignando al Alto Comisario funciones inspectoras sobre las autoridades y servicios de orden civil en Ceuta y Melilla y territorios de soberanía española; el Decreto de 19-VII-1933 concediendo al Alto Comisario la autoridad de Gobernador Civil de Ceuta y Melilla; o, finalmente, el Decreto de 23-IX-1946 sobre funciones y competencias del Gobierno general de las Plazas de Soberanía, vinculado al Alto Comisario (todos en el Apéndice II). 
Obsesión por la unidad de acción que se declara sin ambages, incluso desde la exposición de motivos de más de una disposición sobre la materia. Así, en el Preámbulo de la Ley de 8-XI-1941, reorganizadora de los servicios de la Alta Comisaría, que transcribiremos literalmente, aunque alguna de sus expresiones nos retrotraigan a una época pretérita y muy caracterizada de la historia de España:

Ninguna de las disposiciones dictadas para articular de una manera orgánica los servicios de la Alta Comisaría ... logró captar... el sentido de unidad y continuidad que así en lo político como en lo administrativo debía presidir ...nuestra acción en los territorios africanos.

En esas disposiciones se reconocían al Alto Comisario los poderes más amplios, regulándose más tarde sus relaciones con el Gobierno a través de la Dirección General de Marruecos y Colonias, como órgano asesor del Departamente ministerial a que estaba afecta $y$, sobre todo, continuador de un criterio a seguir en nuestra Zona del Protectorado que había de tener precisamente dicho carácter a través de las vicisitudes políticas del país protector. La guerra de liberación de España, obligando - de un lado- a una actuación diligente en Marruecos y, de otra parte, las dificultades inherentes al funcionamiento de dicha Dirección que hubo de crearse de modo provisional, aconsejaron, en la coordinación de las atribuciones de ambos organismos, normas diligentes, flexibles $y$ hasta necesariamente autónomas. Pero, terminada gloriosamente esa guerra, normalizado el funcionamiento administrativo de la Zona, y en marcha este nuevo acoplamiento de los servicios, es llegado el momento de que se cumpla en todas sus partes la finalidad para la que fue creada en 1925 la Dirección General de Marruecos y Colonias, para que, sin merma de esos poderes más amplios del supremo representante de España en Africa, se garantice la continuidad de la acción y el debido nexo entre la Administración del Protectorado con la Administración española, mediante un contacto directo que se estimaba y se estima en justicia del mayor interés. 
Unidad de dirección y de acción no quieren decir, sin embargo, unicidad de órganos de ejecución. Y ello porque aquellas se ejercen sobre ámbitos territoriales y de soberanía distintos, por la gravitación de los Tratados internacionales y la limitación al libre desarrollo de aquellas que suponen, y por el gradual cambio de carácter que la misma acción sufre en virtud de las posiblidades que se abren a su despliegue.

Significa ello que en el Archivo General de la Administración nos encontramos con documentanción generada por Centros directivos y órganos de ejecución de la Acción española en el Norte de Africa diversos, en función de las diferentes etapas por la que aquella atraviesa. Como desde el punto de vista archivístico el conocimiento de los organismos generadores de la documentación constituye un primer paso inevitable si se aspira a la correcta organización y difusión de los fondos documentales, enumerémoslos:

En una primera etapa, de acción primordialmente diplomática, subsidiariamente militar, y con un telón de fondo siempre económico, los Centros directivos al más alto nivel se encuadran en el Ministerio de Estado (Sección de Política, luego de Marruecos); o en el de la Guerra (Negociado de Marruecos). La dirección y ejecución sobre el terreno, que abarca a todo Marruecos, corresponde a la Legación de España en Tánger y a los Consulados que la asisten en todo el Imperio Jerifiano. Esta fase se encuentra represetnada por la denominada "Sección Histórica" del Grupo de Fondos de Africa.

La segunda etapa se abre con el R. D. de 27-II-1913, creador del Protectorado como estructura de intervención política y administrativa en una determinada Zona de Marruecos. Surge una Administración del Protectorado, en la que se encuadran de lleno los Consulados españoles en la Zona. Como resultado de la acción de tal Administración nace a su vez una Administración marroquí, primero con la denominación de Jalifiana, y más adelante, con la definitiva de Administración del Majzén, independiente en cuanto a soberanía de la del Protectorado, pero intervenida por esta. La acción diplomática para todo el Imperio sigue corriendo a cargo de la Legación en Tánger, peor sólo en lo que concierne a la representación general ante el Sultán y las potencias, con miras fundamentalmente al mantenimiento del statu quo en Tánger hasta tanto no adquiera este una organización político-administrativa porpia en el Convenio de 18-XII-1923/7-II-1924. 
Es hacia finales de esta fase cuando el Centro directivo de incardinarse la Acción española pasa a administrativamente, y con carácter definitivo, en la Presidencia del Consejo de Ministros. Documentalmente la etapa halla su reflejo en el Archivo General de la Administración, por un lado, en el Fondo de la Dirección de Marruecos y Colonias, y, por otro, en el Grupo de Fondos del Protectorado. (Como es lógico, la producción documental de de la Administración primero Jalifiana y luego Majzén hoy día se encuentra custodiada, al menos por lo que toca a las postrimerías del Protectorado, en los Archivos del Reino de Marruecos, aunque el reflejo de su intervención por la del Protectorado figure en el Grupo de Fondos de éste).

Una tercera etapa se inaugura a partir del Convenio que organiza el Estatuto de Tánger, acuerdo que define una Zona con un legislativo, un ejecutivo y un judicial propios, y una administración no soberana, pero sí autónoma del Imperio jerifiano y participada por los representantes consulares de las potencias. La Acción de España sobre el terreno se bifurca en su ejecución con arreglo a esta división jurisdiccional en Zonas, aunque la superior unidad de dirección quede garantizada por su ejercicio continuado a cargo de la Dirección General de Marruecos y Colonias.

En la Zona de Tánger, tal Acción corre por cuenta del Cónsul General, ya que desaparece la Legación. En la del Protectorado, el Alto Comisario, amén de concentrar en sus manos toda la alta intervención política y administrativa en el territorio y las relaciones diplomáticas con los representantes de las potencias para todos los asuntos concernientes a la Zona, asume la gobernación general y la inspección de las plazas de soberanía española, entre ellas Melilla. La creación por R. D. Ley el 15-XII-1925 de la Dirección General de Marruecos y Colonias, adscrita a la Presidencia del Consejo de Ministros, pone el colofón al proceso de configuración del Centro Directivo superior de toda la Acción española en Marruecos, pese a posteriores vicisitudes administrativas de poca entidad.

Una cuarta etapa, que se dilata ya hasta la independencia del Reino de Marruecos, podemos fijarla a partir del 9-XI-1940. En su decurso, todos los resortes de la Acción sobre el terreno se concentran en manos de la Alta Comisaría.

Concluyamos, pues, este panorama reiterando cómo tal unidad de acción ha permitido reunir en el Archivo General de la Administración un Grupo de Fondos dotado de unos atributos de exhaustividad e interco- 
nexión como rara vez suelen darse en los depósitos de archivos: una verdadera universitas rerum, en el sentido que, como nos recuerda Michel Duchein, los archiveros alemanes e italianos dan a este concepto archivístico, y cuya presencia en cualquier agrupación documental estiman imprescindible para que ésta adquiera la condición de fondo de archivo - necesariamente "cerrado" o "concluso" (2) - y no digamos ya para que se pueda hablar de Grupo de Fondos.

VIAB DB ACGBSO ACTUALBB A LA INFOAMACION 8OBRB LA

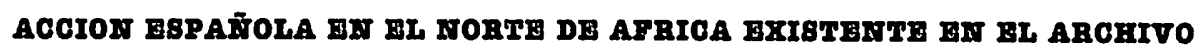
GSWEBAI DE IA ADMTWI8TRACION DEL B8TADO

Sin embargo, comodidad de acceso físico para el investigador no significa necesariamente facilidad de acceso intelectual. El enorme volumen de documentos, acumulado, la cambiante adscripción administrativa de los órganos generadores, la sutileza del entramado de vínculos orgánicos y funcionales impuesta desde un principio por la complicación del tablero diplomático internacional y el carácter paulatino de la penetración española, hacen que en el pasado no haya resultado fácil - ahora tampoco lo esdar un tratamiento archivístico riguroso a esta agrupación documental (3).

Si para el investigador resulta sin duda una tentación irresistible acudir a estas fuentes por su riqueza y exhaustividad, para el profesional de archivos supone un reto difícilmente superable tratar de dotarlas de una organización adecuada. $Y$ es que, tanto por su génesis, como en parte, por su proceso mismo de acumulación - recordemos que entre ambos media un fenómeno tan paradigmático desde el punto de vista archivístico como la independencia de un país y la retirada de la potencia ocupante-, ponen sobre el tapete la operatividad o no de los conceptos fundamentales de la profesión: "respeto del fondo", "principio de procedencia", "principio de respeto al orden originario", "carácter cerrado o abierto de los fondos" (4).

Tomados en su conjunto tales conceptos o principios hacen referencia en su aplicación al objetivo de dotar de una adecuada organización o reorganización interna a un determinado fondo; es decir, de identificar las distintas secciones y series documentales que las componen, con arreglo a las pautas que nos marca el proceso orgánico de su creación.

Nuestra meta es más modesta. Y no puede ser de otro modo, puesto que toda actividad de organización interna de un fondo exige un con- 
tacto estrecho con la documentación y un estudio minucioso de la totalidad de la normativa pertinente. Se comprende que tal tarea - caso de ser necesaria, y no ceñirse el problema a una mera cuestión de descripción- sólo pueda ser llevada a buen término por los técnicos de archivos del A.G.A.

Pero existe otra clasificación, más elemental si se quiere, pero de gran utilidad a la hora de orientar a los investigadores en un depósito de archivos, y que - al menos en el plano de las propuestas - si está al alcance del archivero que disponga de instrumentos de descripción lo suficientemente explícitos. Se trata de la clasificación externa de los fondos custodiados en una institución de archivos, que los distribuye en Grupos y Subgrupos de Fondos de naturaleza análoga por responder su génesis a una gran función de la Administración, e incluso a materias competenciales análogas.

El resultado de semejante clasificación es que el investigador obtiene una idea clara de las grandes estructuras de una Administración, y encuentra reunidos los instrumentos de descripción que pueden interesarle.

Sin embargo, para que una clasificación externa de esta índole sea correcta, ha de respetar ineludiblemente la integridad de los fondos (5). De aquí la operatividad del artículo de $\mathrm{M}$. Duchein, que se ocupa pormenorizadamente de las cautelas necesarias para no romper tal integridad. Operatividad que se ve reforzada, subrayémoslo de nuevo, por el hecho de que la totalidad de los fondos que nos ocupan son "cerrados", por haber desaparecido los organismos que los produjeron y no haber heredado sus funciones otros.

Precisemos, con todo, que la dificultad de acceso a que antes hacíamos referencia no proviene tanto de que los fondos estén desorganizados, ni mucho menos sin identificar, sino de que la forma de presentación de los instrumentos de descripción no resalta quizá con toda la evidencia deseable la configuración de cada uno de ellos y su vinculación con el resto. Ello tiene su explicación si se toma en cuenta la forma en que fueron transferidos al Archivo General de la Administración, que obligó por modo inevitable a realizar un registro topográfico, como etapa metodológica previa a la identificación de fondos y su descripción sistemática, la cual, como no ignoramos, ha de plasmarse en un inventario. Por el contrario podemos afirmar que este grupo de fondos cuenta hoy día con suficientes instrumentos de descripción como para permitir el acceso y la explotación de cualquier unidad de instalación. 
Pero basta ya de consideraciones generales y, como mejor medio de abordar el tema, enumeremos ya con qué instrumentos de acceso se encuentra el investigador que pretende trabajar en la Sección de Africa del Archivo General de la Administración, y a qué grupos documentales supuestamente responden. En una etapa ulterior desglosaremos cada uno de tales grupos documentales en los fondos que en rigor los constituyen, para, desde la modestia de nuestros planteamientos, proponer una reorganización o clasificación externa que suponga para el estudioso una verdadera Guía a lo que, de lo contrario, y pese al grado de profundidad analítica de los asientos descriptivos, permanecería en un estado de nebulosa.

\section{Sección "Zistórioa"}

Como el resto de la primera documentación ingresada en el Archivo General de la Administración fue transferida por la extinta Dirección General de Plazas y Provincias Africanas. Realizado ya un Registro Topográfico de sus unidades, pueden apreciarse los fondos que la constituyen. Incluye documentación de las antiguas Secciones de Política y Marruecos del Ministerio de Estado, Legación de España en Tánger, Consulado General en Tánger y, quizás, de algunos Consulados de España en lo que luego sería Zona del Protectorado Español, pero también probablemente en Zona del Protectorado Francés. Por lo que toca a estos dos últimos extremos, sin embargo, la presentación del Registro, que no sigue un orden sistemático por procedencias, hace que ello no se pueda afirmar con seguridad (nos inclinamos a pensar que más bien se trata de series de correspondencia de la Legación y Consulado General en Tánger con los Consulados dependientes).

Su ámbito cronológico abarca desde finales del siglo XVIII, para la documentación de Consulados - ¿o sólo del Consulado en Tánger?-, hasta 1936: el grueso de la documentación, con todo, se encuadra temporalmente entre 1850 y 1916.

Bien se echa de ver que su categorización como "Fondo o Sección Histórica" le fue asignada por corresponderse, aproximativamente, con lo que viene a ser la primera etapa en un proceso de colonización. Sabido es que la penetración diplomática, apoyada en mayor o menor medida por la militar, y guiada y motivada por la económica, precede al proceso de ocupación y organización administrativa de un territorio. En la Acción espa- 
ñola en Marruecos, ello se trasluce con claridad siguiendo la línea que va, con alternativas, desde la pura actividad diplomática y militar de los comienzos a la instauración de una Administración en el Protectorado con una dimensión civil creciente, para finalizar en la coexistencia de dos Administraciones plenamente estructuradas y adultas en un mismo territorio: La Administración del Protectorado y la Administración del Majzén (6).

Sin embargo, no estamos tan seguros de que, archivísticamente, la adscripción a esta Sección Documental de los distintos fondos que de una manera no suficientemente identificada la componen sea plenamente satisfactoria.

En primer lugar, señalemos que los fondos que componen este grupo no responden a la misma gran función administrativa: el de las Secciones del Ministerio de Estado constituye el "precedente histórico" del Centro Directivo de toda la Acción de España en el Norte de Africa; cl de la Legación en Tánger (y quizás intermitentemente - según la evolución del rango de la representación diplomática española - el del Consulado General en la misma ciudad) corresponde al "precedente histórico" de la dirección sobre el terreno, o si se prefiere, de la ejecución de dicha Acción.

Además uno de los fondos que integran este Grupo o "Sección Histórica" - el de la Legación en Tánger- se halla en la actualidad desmembrado. En efecto, en la Sección de Asuntos Exteriores del A.G.A., y remitida por el Departamento de la misma denominación se custodia documentación de dicha Legación (7) de fechas comprendidas entre 1858 y 1918, aunque con representación escasa de las series políticas (precisamente por menudear éstas en la "Sección Histórica" de Africa).

No nos parece, pues, que la configuración actual de este Grupo de Fondos o "Sección Histórica" sea correcta, al no cumplir ninguna de las dos condiciones básicas a que nos referíamos al tratar de la clasificación externa. Examinaremos, por consiguiente, con detenimiento cada uno de los fondos o fracciones de fondos que la integran, para tratar de fijar su encuadre adecuado.

Por lo que respecta a la documentación producida por las Secciones del Ministerio de Estado con competencia en los asuntos de Marruecos y Colonias españolas en Africa, no es dudoso que en su día constituyeron un fondo diferenciado. En efecto, su organismo productor satisfizo los diversos criterios que en este orden fija Duchein (Vid. artículo citado, 
pág. 79): las Secciones del Ministerio de Estado tuvieron una existencia jurídica propia en virtud de una norma de creación concreta y datada; gozaron de competencias precisas y estables; ostentaron una posición clara en la jerarquía administrativa, y a su frente estuvo una Autoridad con facultades resolutorias.

No obstante, con el traslado de sus competencias a la Presidencia del Consejo de Ministros, muchos de los expedientes que habían generado las Secciones del Ministerio de Estado fueron transferidos a la Dirección General de Marruecos y Colonias, por resultar imprescindibles para la gestión administrativa del órgano recién nacido. Hoy día se encuentran inexplicablemente entremezclados con los propiamente producidos por la citada Dirección.

Plantéase por consiguiente, la cuestión de si hemos de considerar un fondo diferenciado y qué procedencia hemos de atribuir a la documentación de las Secciones de Estado, presente en la "Sección Histórica". La clave de la solución estriba en la medida en que los expedientes que en su día generaron estén entremezclados con los de la Dirección General de Marruecos y Colonias.

Si cabe considerarlos entrelazados totalmente y sin remedio con los de la Dirección, no constituirán fondo diferenciado (Véase sobre la nota de totalidad y Duchein, art. cit., pág. 83) , y su procedencia será dicha Dirección (Ibid., pág. 84). Deberán integrarse, pues, en un único fondo con el de la Dirección General de Marruecos y Colonias.

Si por el contrario no estimamos excesiva la confluencia de expedientes, podremos apreciar la existencia de un fondo diferenciado con la denominación de Fondo del Ministerio de Estado. Como la decisión en uno $\mathbf{u}$ otro sentido depende del estudio pormenorizado y de primera mano de la documentación, lo más prudente parece constituir un Grupo de Fondos de Centros Directivos de la Acción de España en el Norte de Africa, compuesto de un segmento "histórico" —el Fondo de Estado- y por el Fondo de la Dirección General de Marruecos y Colonias.

En el caso de la Legación en Tánger, el problema primordial no es el de si representa o no un fondo - la cosa es a todas luces evidente,- sino el de reconstituir un fondo desmembrado por la distribución de fracciones del mismo entre las Secciones de Africa y Asuntos Exteriores del 
A.G.A. Ello puede hacerse sobre inventario, pero la solución óptima estriba en la integración física de la documentación (8).

En cuanto al encuadre global de todo este fondo, nos parece evidente que, al igual que los fondos del Protectorado o los del Consulado en Tánger, supone un reflejo de la Acción de España sobre el terreno. Debiera en nuestra opinión integrarse en un grupo de fondos de Ejecución de la Acción Española en el Norte de Africa, del que formarían también parte en calidad de Subgrupos los Fondos del Protectorado y el Fondo del Consulado en Tánger. El de la Legación en esta ciudad, fondo "cerrado" ya en 1924, constituiría el "precedente histórico" de la Acción de España sobre el terreno.

En todo caso lo que resulta ya impostergable es la redacción de un inventario por procedencias para la mencionada "Sección Histórica".

\section{Fondo de la Dirección General de Marruecos y Colonias}

Fue transferido al Archivo General de la Administración junto con el anterior procedente e la Dirección General de Plazas y Provincias Africanas. Contiene documentación comprendida entre los años 1799 y 1947.

Se trata del fondo generado por los distintos órganos que fueron ocupándose, primero en el Ministerio de Estado, y luego en la Presidencia del Consejo de Ministros, de la gestión de los asuntos de Marruecos y otras colonias españolas en Africa (por ejemplo, Sidi Ifni o el Sáhara). Procedencias orgánicas (la procedencia archivística es una como veremos, la Dirección General de Marruecos y Colonias) que se encuentran representadas en este fondo son, pues, las Secciones de Política, de Colonial o de Marruecos, del Ministerio de Estado; la Oficina de Marruecos de la Presidencia del Gobierno, la Dirección General de Marruecos y Colonias de la Presidencia del Consejo la Secretaría Técnica de Marruecos del mismo Departamento.

Advirtamos que en el fondo de la Dirección General de Plazas y Provincias Africanas figuran documentos que por sus fechas pensamos pudieran tener que integrarse en el fondo que nos ocupa, pues existe la posibilidad que su ubicación actual se deba a las condiciones de realización de la transferencia.

El fondo cuenta con un denominado "Indice del Archivo General", verdadero cuadro de clasificación de fondos, o si se prefiere, inventa- 
rio somero (9). Para alguna de las Secciones del cuadro -las de Política, Religión, Sanidad, Justicia y Enseñanza - se ha elaborado ya un inventario a cargo de doña Pilar Casado Liso y colaboradores. Sin embargo, el "Indice" mantiene su utilidad como una primera introducción, incluso a las Secciones inventariadas, al facilitar una visión global de la estructura en series de las mismas, visión que queda un tanto difuminada en el inventario por la profundidad analítica de los asientos. Para las Secciones del Fondo no inventariadas, el "Indice" o Cuadro resulta de uso ineludible. Señalemos también que la Sección de Personal ha sido indizada en fichas.

La mejor Guía del Fondo será, pues, transcribir aquí los principales apartados del "Indice". Cuando en los mismos aparezcan menciones a Melilla o Ceuta, descenderemos al nivel de la serie documental, pero hemos de advertir que las noticias que ahora demos sobre Melilla se repiten, para las Secciones que cuentan con inventario, con algunas de las que facilitamos más adelante, ya que éstas se han tomado, incluyendo signatura, del último de los instrumentos de descripción citados.

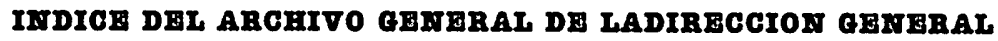
DE MARRUECOS Y COLONIAS

I. PERSONAL (indizada)

A. Parte General 0/2. Disposiciones generales

B. Parte especial $0 / 3$. Expedientes personales de funcionarios

C. Expedientes personales de cesantes.

D. Pretendientes

II. COMERCIO (inventariada)

A. Aduanas

1.a Aduanas de Melilla y su campo

1.b Aduanas de Ceuta

B. Información comercial

C. Medios comerciales

D. Dificultades comerciales

1. En la Zona y plazas españolas 

E. Reclamaciones y peticiones
F. Puertos (Servicios)
G. Navegación
H. Varios

III. AGRICULTURA, INDUSTRIA Y TRABAJO
A. Agricultura
B. Industria 2.a Minas
C. Trabajo

IV. RELIGION (inventariada)
A. Religión católica
3. Iglesias y capillas.

B. Islamismo

2. Mezquitas

C. Otras religiones

V. JUSTICIA (inventariada)
A. Organización judicial
B. Actuación judicial
C. Régimen inmobiliario
D. Incidentes
E. Varios
F. Estadísticas
G. Registro Civil
H. Organización Notarial
I. Ejército de profesiones judiciales en la Zona

VI. ENSEÑANZA (inventariada)
A. Parte general
3. Pensiones y subvenciones para estudios a moros, hebreos $\mathrm{y}$ otros.
B. Escuelas
2. Escuelas de Melilla y su región 
VII. BIENES Y RENTAS
A. Bienes del Estado
B. Bienes del Majzén
C. Bienes Habus
D. Bienes particulares
E. Rentas-tabacos
F. Impuestos e ingresos varios

VIII. SANIDAD (inventariada)
A. Parte general
B. Establecimientos sanitarios
C. Estado sanitario
D. Beneficencia
E. Medicamentos
F. Farmacias y farmacéuticos
G. Cementerios

IX. SERVIGIOS LOCALES
A. Parte general
B. Urbanización
C. Varios
D. Juntas de reclutamiento

X. OBRAS PUBLICAS
A. Parte general
B. Puertos

6. Melilla

7. Ceuta

10. Faros (construcciones, servicios, etc).

C. Carreteras

D. Ferrocarriles

3. Tánger-Fez

4. Ceuta-Tetuán 
5. Nador-Tetuán-Tiztutín-Tafersit

6. Larache-AlcAzaquivir

7. Ferrocarriles varios

E. Caja Especial

F. Abastecimiento de aguas

G. Proyectos de Obras Públicas (con índice aparte)

XI. COMUNICACIONES
A. Correos
B. Telégrafos
C. Radiotelegrafía y Radiotelefonía
D. Cables
E. Teléfonos
F. Aviación
G. Comunicaciones por ferrocarril, carreteras y marítimas
H. Disposiciones generales referentes a varios servicios
I. Comunicaciones submarinas

XII. POLITICA (inventariada)
A. Organización de la Zona
B. Negociaciones, Tratados, convenios y conferencias internacionales
G. Nacionalidad
D. Protección
E. Representantes diplomáticos y consulares extranjeros y españoles
F. Incidentes
G. Orden Público
H. Reclamaciones
I. Africanismo
J. Política general
K. Guerra Europea
L. Límites
M. Cartografía, topografía, etc., Geodesia
N. Prensa 
XIII. CONTABILIDAD

A. Presupuestos y disposiciones generales

B. Gastos reservados

1. Tetuán y Melilla

C. Gastos de personal

D. Gastos de material

E. Gastos de los Consulados

F. Varios

G. Empréstitos

H. Organismo Central Peninsular-Sección de los Presupuestos Generales "Acción en Marruecos"

I. Tribunal de Guentas

J. Servicio de Intervención económica legal del Protectorado.

XIV. ARCHIVO DE TANGER

A. Estatuto

B. Comercio, Industria, Navegación y Trabajo

870

C. Sociedades, Asociaciones, etc.

D. Servicios Locales

E. Enseñanza

F. Política

G. Orden Público e incidentes

H. Justicia

I. Sanidad

J. Prensa

K. Varios

L. Consulado General

M. Obras públicas

N. Comunicaciones

O. Personal de la Administración Internacional

P. Fuerza Armada

Q. Presupuestos de la Administración Internacional

R. Empréstitos

S. Oficina Mixta de Información

T. Religión 


\section{Fondo de la Dirección General de Plazas y Provincias Africanas}

Su ámbito cronológico se extiende de 1907 a 1960, incluye documentación referente al Marruecos anterior a la Independencia; cabe, pues. plantearse si tales documentos no estarán ubicados incorrectamente como resultado de la transferencia y si no deberán integrarse en el Fondo anterior.

\section{Subgrupo de Fondos del Protectorado}

Lo compone el conjunto de documentos generados por el Alto Comisario, órganos directamente vinculados a éste y órganos superiores de la Administración del Protectorado, desde la fecha del primer Reglamento de constitución del mismo hasta la Independencia del Reino de Marruecos.

Representa un total de 10.890 legajos y abarca desde los años 1911 a 1956. Como instrumento de descripción cuenta con un Inventario General en fichas. También en este caso se ha confeccionado por dona Pilar Casado Liso y colaboradores un inventario analítico de gran parte del Subgrupo.

Hemos de considerarlo una verdadera agrupación de Fondos ya que sus divisiones se corresponden con procedencias orgánicas que no coexistieron siempre en el tiempo. Sin embargo, se echa de menos la presencia de referencias cruzadas que remitan de cada gran división administrativa a la que le sucede o precede en el tiempo.

Responde, pues, en la actualidad a una clasificación por tramos cronológicos, pero no realizada de modo coherente. había que plantearse sin más demora la conveniencia de dotarlo de una verdadera clasificación orgánico-funcional, o, en su defecto, de realizar un inventario interfondos.

Pero pasemos ya a relacionar los diferentes fondos que lo componen, con sus principales Secciones documentales:

Arahivo General del Protectorado

1. Expedientes personales

2. Expedientes de asuntos

Secretaria General

1. Expedientes personales

2. Asesoría Jurídica-Secretaría Político-Económica 
3. Asuntos Generales

4. Política, Información

5. Asuntos por personas y asuntos reservados

6. Industria. Comisaría de Multas

7. Gobernación

8. Presidencia, Plazas de Soberanía, Marina, Pesca, etc.

9. Guerra, Trabajo, Colonización, Gracia y Justicia, Obras Públicas y Hacienda

Delegación General

1. Personal

2. Contabilidad

Delegación de Asuntos Indígenas

1. Personal

2. Asuntos

3. Política

4. Información

5. Nacionalismo, Terrorismo

6. Cartas políticas de las Intervenciones y Resúmenes de situación

7. Peregrinaciones a la Meca. Sequía. Bienes Habús. Pascua de Aid-el-Quebir

8. Interpretación

9. Sección de Ifni y Sáhara

- 10. Correspondencia de españolas con marroquíes y asuntos varios

11. Controles

12. Documentos pendientes de clasificar

13. Registro General

14. Contabilidad

Organismos dependientes de la Delegación de Asuntos Indigenas

1. Asuntos varios

2. Personal 
Acción Benéfico-social

1. Personal Europeo e Indígena

2. Asuntos

3. Propuestas

4. Contabilidad

Academia de Interventores $\theta$ Interventores

1. Expedientes personales de alumnos

2. Cursos de perfeccionamiento

3. Expedientes de personal al servicio de intervenciones

4. Expedientes de Asuntos generales, Interventores honorarios

5. Expedientes de Asuntos relacionados con la Academia de Interventores y Cartas a los Interventores

Subinspección de Fuerzas Jaltfianas

1. Expedientes de Personal Europeo

2. Hojas de Servicio de Jefes

3. Asuntos Generales

4. Remonta

Mehasnias y Mehal-las

-Mehasnías

1. Personal Europeo e Indígena

2. Asuntos

3. Estado de Altas y Bajas. Estados de situación

4. Hacienda. Contabilidad

5. Intervención de Asuntos Marroquíes en España y Asuntos relacionados con la Guerra Givil Española.

-Mehal-las

1. Mehal-la de Tetuán núm. 1

2. Mehal-la Jalifiana de Melilla núm. 2

3. Mehal-las Jalifiana de Larache núm. 3, del Rif núm. 5 y de Kert núm. 6 
Intervención territorial del Kert

Intervención territorial de Melilla

Intervención territorial del Rif

Intervención territorial de Gomara-Xauen

Intervención territorial del Lucus

Intervención territorial de Yebala

Yebala. Regional de Tánger

(Cada uno de estos fondos se distribuye en las Secciones y series de Personal, Expedientes personales y de Asuntos por Personas, Politica e Información, Registro y Contabilidad).

Delegación de Educación y Cultura

1. Expedientes de Personal y varios

2. Expedientes de maestros

3. Expedientes de estudiantes y becarios

4. Asuntos relacionados con la Enseñanza y propios de esta

Delegación.

5. Secretaría de Cultura

Delegaciones de Economia, Industria y Comercio, Obras Públicas y Hacienda

Peñón de Vélez de la Gomera

Arahivo de don Clemente Cerdeira

La información sobre la orientación política general de la Acción de España en Marruecos a cargo de la Alta Comisaría ha de buscarse en la serie de "Expedientes de asuntos" del Fondo "Archivo General del Protecto- 
rado", que cubre los años 1915 a 1941; o en la serie de "Política" del fondo de la Secretaría General, que abraza cronológicamente de 1911 a 1956.

Para localizar información referente a Melilla y Ceuta - aparte de lo que con claridad se desprende del Cuadro de Clasificación que acabamos de relacionar-, hemos de tener en cuenta el R. D.-Ley 31-X-1927, que asigna la tramitación de los asuntos de orden civil de las plazas de soberanía a una Secretaría de Gobierno adscrita a la Delegación General; y la Ley 8-XI-1941, que atribuye idéntica tramitación a la Sección de Asuntos de los territorios de Soberanía de la Secretaría del Alto Comisario. Parece poco dudoso, pues, que su ubicación actual es el apartado $8^{\circ}$ ("presidencia, Plazas de Soberanía, Marina, Pesca, etc.") del Fondo de SECRETARIA GENERAL del citado Cuadro de Clasificación de Fondos (legs. 3502-3511).

Finalicemos esta revista del conjunto documental referente a Marruecos dentro de la Sección formulando nuestra propuesta de clasificación externa de dicho conjunto. $1^{\circ}$ ) Un grupo de fondos de Centros Directivos de la Acción Española en el Norte de Africa, integrado por un fondo del Ministerio de Estado de carácter histórico, el fondo de la Dirección General de Marruecos y Colonias y el fondo de la Dirección General de Plazas y Provincias Africanas; $2^{\circ}$ ) Un grupo de fondos de Centros de Ejecución de la Acción Española en el Norte de Africa, compuesto por el Subgrupo de fondos del Protectorado, el fondo de la Legación en Tánger y el del Consulado en la misma ciudad. Para estos dos últimos fondos, cabe plantearse la posibilidad de incluirlos en un Subgrupo de fondos relativos a Tánger.

En cualquier caso, y a fin de facilitar elementos de enjuiciamiento de la propuesta anterior, así como para brindar al investigador una primera orientación, se incluye en los Apéndices I, II y III una reseña básica del marco legislativo en que se encuadró la Acción Española en el Norte de Africa. 
ALGUNAS WOTIGIAS REFERENTGS A MELILLA ESPIGADAS FN LOS INSTEUMANTOS DE DESCRIPCION DE LOS FONDOS QUB NOS OCUPAN

Nos ceñiremos en nuestra selección a lo que parece ser el tema de interés primordial en estas Jornadas, centradas en aspectos como la historia del trazado de la ciudad, su arquitectura, la presencia judía en ella, etc.

Antes de pasar propiamente al Grupo de Fondos de Africa, citaremos, dentro del fondo de la Legación en Tánger, en el Grupo de Asuntos Exteriores:

- Negociaciones para establecer límites, Aduanas y suministros de víveres en Ceuta y Melilla. Años 1860-1890. Caja A. E. 3.029.

- Idem. Años 1860-1888, Caja A. E. 3.034.

- Sobre desviación del Río Oro en Melilla, años 1869-1871. Caja A. E. 3.037.

- Ataque de los rifeños en melilla, año 1871, Caja A. E. 3.037.

- Importación de víveres a Melilla. Años 1866-1876. Caja A. E. 3.037.

Ya en el Grupo de Africa, entresaquemos de los fondos de la "Sección Histórica": $\mathrm{AF}-\mathrm{M} 75$.

- Legación en Tánger: Melilla, obras en el río. Año 1896, Caja

- Legación en Tánger: Melilla: Alumbrado marítimo, costa del Rif y establecimiento de un Faro en Tres Forcas y Cabo Quilates. Años 1906-1911. Caja AF-M 77.

- Melilla: Problema de límites. Caja AF-M 113.

- Ensanche de los límites de Melilla. Años 1895-1897. Caja AF-M 130.

- Idem. Años 1908-1910. Caja AF-M 132

- Melilla: Creación de una Escuela de Primera Enseñanza para Niños Indígenas. Caja AF-M 133.

- Construcción del Faro en el Cabo de Tres Forcas, años 1907-1912. Caja AF-M 133.

Rebelión de rifeños por trabajos de fortificación dentro de Melilla. Caja AF-M 135. 
Caja AF-M 136.

- Construcción de un cementerio en Melilla. Años 1894-1898, Caja AF-M 138.

- Obras en carreteras y aduanas de Melilla. Años 1910-1913.

- Melilla: Proyecto de colonización en la zona exterior. Años 1900-1904. Caja AF-M 232. $\mathrm{AF}-\mathrm{M} 150$

- Aprovisionamiento de Melilla. Años 1881-1894. Caja

- Asociación Mercantil de Melilla: Informes sobre el Comercio de la Plaza: construcción del puerto, aduanas. Año 1903. Caja AF-M 165.

- Límites de Melilla. Años 1859-1860. Caja Af-M 172.

- Replanteamiento de los límites de Melilla. Años 1889-1893. Caja AF-M 174.

- Melilla: Reclamación de indemnizaciones por los terrenos expropiados para la ampliación de sus límites. Años 1845-1868. Caja AF-M 183.

- Plano general de las colonias agrícolas de la Sociedad Norteafricana y otros documentos sobre la misma. Años 1892-1897. Caja AF-M 184.

- Propuesta de arbitrios para la ejecución de las obras del Puerto de Melilla. Años 1903-1907, Caja Af-M 198.

- Acción de la Junta de Arbitrios de Melilla. Años 1903-1907. Caja AF-M 198.

- Asociación Mercantil e Industrial de Propietarios de Melilla: Solicitud de reformas en la Plaza y de permisos de exportación de ganado. Caja AF-M 198.

- Refugio de moros y hebreos en Melilla acogiéndose al pabellón nacional. Años 1903-1907. Caja AF-M 198.

- Colonización del Campo exterior de la Plaza de Melilla. Años 1897-1901. Caja AF-M 199. $\mathrm{AF}-\mathrm{M} 209$.

- Abastecimiento de carne para Melilla. Año 1868. Caja

- Melilla: Proyecto de colonización en la Zona exterior. Años 1900-1904. Caja AF-M 232.

- Familias hebreas que solicitan establecerse en el Campo de Melilla. Año 1882. Caja AF-M 327. 
- Actitud de los hebreos en Marruecos, Caja AF-M 327.

De la serie "Proyectos de Obras Públicas" (serie $\mathrm{X}-\mathrm{G}$ ) del fondo de la Dirección General de Marruecos y Colonias, seleccionemos:

- Residencia de Estudiantes Marroquíes en Melilla. Años 1927 y 1930. Legs. X-G núms. 6 y 7.

- Ferrocarriles: Melilla y Zona Francesa. Año 1927. Leg. X-G núm. 15. núm. 28.

- Carretera Melilla-Río Muluya. Años 1929-1935. Leg. X-G núms. 38 a 49 .

- Carretera Tetuán-Melilla. Años 1929-1935. Legs. X-G.

- Estercolera en la Granja Experimental de Melilla. Año 1935. Leg. X-G núm. 60. núm. 28.

\section{CONDICIONHS DJ ACCESO A ESTOB FONDOB}

Al igual que ocurre con el resto de la documentación generada por organismos públicos, la consulta de estos fondos viene regulada por los artículos pertinentes de la Ley 16/85 del Patrimonio Histórico Español. No obstante, la especial índole de los datos contenidos en ellos con frecuencia -cuyo conocimiento o difusión puede incidir sobre la seguridad y defensa del Estado o las buenas relaciones de España con otros países- hace que en su caso sea preceptivo solicitar la autorización de consulta a la Secretaría General Técnica del Ministerio de Relaciones con las Cortes. La autorización se tramita a través del Archivo Central del Departamento, adonde debe remitirse la solicitud.

Como quiera que para decidir sobre lo procedencia o no de conceder la autorización se recaba del A.G.A., un informe sobre el contenido de los documentos, es recomendable que el investigador, para ganar tiempo, acuda en primer lugar a dicho Archivo, a fin de seleccionar en los instrumentos de descripción las unidades documentales que considera de interés. Tales unidades ha de incluirlas en la solicitud que con posterioridad formule en el Archivo Central del Ministerio de Relaciones con las Cortes. 


\section{APENDICW I}

Marco legislativo del Subgrupo de Fondos de la Dirección General de Marruecos y Colonias.

12-1-1852 Reglamento Interior de la Primera Secretaría de Estado que establece una Sección Primera, encargada, entre otras atribuciones, de los negocios de los agentes diplomáticos y consulares españoles en ... Berbería y Marruecos.

21-1-1854 R. D. (Ministerio de Estado) que asigna la competencia anterior al Negociado de Política de Europa de la Dirección de Política.

25-1-1875 Decreto (Ministerio de Estado) que asigna la competencia en cuestión a la Sección de Asuntos Políticos.

25-9-1888/1-10-1888 R. D. (Ministerio de Estado) y R. O. de desarrollo reglamentario que establece la Sección de Política de Asia, Africa y Oceanía.

16-8-1899 R. D. (Ministerio de Estado) que asigna la competencia estudiada a la Sección de Política.

30-12-1901 R. O. (Ministerio de Estado) que asigna la competencia estudiada a la Sección de Política.

30-12-1901 R. O. (Ministerio de Estado) que establece las Secciones de Política y Colonial.

27-11-1912 Creación en el Ministerio de Estado de la Sección de Marruecos.

18-1-1924 R. D. creando en la Presidencia del Gobierno una Oficina de Marruecos.

"Art. 2.- En lo sucesivo, tanto el Alto Comisario como todas las autoridades que no dependientes de él hayan de relacionarse con el Gobierno en asuntos de Marruecos, se entenderán exclusivamente con la Presidencia..."

"Art. 3.- La Oficina de Marruecos constará de una Secretaría y dos Secciones —una de ellas civil y la otra militar-..."

"Art. 9.- Por ambos Ministerios, Estado y Guerra se hará entrega en momento oportuno a la Presidencia, de la parte de los Archivos de los disueltos Negociados que puedan ser necesarios al nuevo organismo, entregándose por separado, debidamente 
inventariados, todos aquellos expedientes pendientes de trámite o resolución".

15-12-1925 R. D.-Ley creando en la Presidencia del Consejo de Ministros la Dirección General de Marruecos y Colonias.

Organización: a) Una Subdirección General, con una Secretaría y Gabinete de Cifra, una Sección de Asuntos Militares, una Sección de Contabilidad y la Asesoría Técnica de Obras Públicas; b) la Sección Civil de Asuntos de Marruecos; c) la Sección Civil de Asuntos Coloniales.

"Art. 2.- Dicha Dirección General tendrá a su cargo: a) Los asuntos que hasta la fecha han venido dependiendo de la Oficina de Marruecos... y b) Los asuntos que hasta la fecha han venido dependiendo de la Sección Colonial del Ministerio de Estado".

"Art. 13.- Tanto la Oficina de Marruecos, afecta a la Jefatura del Gobierno, como la Sección Colonial del Ministerio de Estado, entregarán en momento oportuno sus respectivos archivos a la Dirección General de Marruecos y Colonias...".

4-1-1926 R. O. (P. del C. de M.) disponiendo que las relaciones oficiales con los Gobiernos extranjeros en orden a la acción de España en la Zona del Protectorado y en sus posesiones del Africa Occidental sean mantenidas por conducto del Ministerio de Estado en estrecha relación con la P. del C.

"1. Las relaciones oficiales con los Gobiernos extranjeros... se mantendrán por conducto del Ministerio de Estado... quien enviará urgentemente a la Pres. del C. de Ministros, con la indicación 'Dir. gen. de Marruecos y Colonias' copia de las notas y comunicaciones oficiales...".

"2. La P. del C. de M. se entenderá directamente con los representantes diplomáticos de S. M. en el extranjero sobre cualquier asunto relacionado con la acción de España en Marruecos y en sus posesiones del Africa Occidental...".

“3. De todas las comunicaciones que, en relación con los asuntos de referencia se dirijan por la $\mathrm{P}$. del $\mathrm{C}$. de $\mathrm{M}$. a los representantes diplomáticos de S. M. en el extranjero se dará conocimiento urgente al Ministerio de Estado". 
18-5-1931 Decreto (P. del C. de M.) declarando subsistente el R. D. de 15-12-1925.

Organización de la Dirección General de Marruecos y Colonias: Tres Secciones (Marruecos, Colonias e Intervención y Contabilidad); una Secretaría: tres Negociados (Militar, de Obras Públicas y de Sanidad).

13-10-1933 Orden (P. del C. de M.) delegando en el Subsecretario las competencias en la materia.

19-7-1934 Decreto (P. del C. de M.) suprimiendo la Dirección General de Marruecos y Colonias, avocando la competencia delegada por Orden de 13-10-1933 al Presidente del Consejo y creando para auxiliar a éste la Secretaría Técnica de Marruecos.

Organización de la Secretaría Técnica: a) Una Sección Civil, subdividida en las Subsecciones de Asuntos Indígenas, Hacienda, Fomento y Asuntos Generales; b) Un Negociado Militar.

25-8-1934 Orden (P. del C. de M.) regulando la organización y funcionamiento de la Secretaría Técnica de Marruecos.

31-12-1935 Decreto (P. del C. de M.) creando la Dirección de Marruecos y Colonias.

Organización: a) Una Secretaría Técnica de Marruecos y Colonias; b) Una Sección de Asuntos Políticos y Generales; c) Una Sección de Asuntos Económicos y Servicio de Intervención.

3-7-1936 Decreto (P. del C. de M.) restableciendo la Dirección General de Marruecos y Colonias.

Organización: a) Secretaría Técnica de Marruecos con dos Secciones, "Asuntos políticos y generales" y "Asuntos Económicos"; b) Secretaría Técnica de Colonias con dos Secciones "Administrativa y Comercial" $y$ "Contabilidad".

30-1-1938 Ley por la que se reorganizan los Servicios Centrales de la Administración del Estado y se adscribe a la Vicepresidencia del Gobierno el Servicio de Marruecos y Colonias.

Organización: Una Sección de Marruecos y otra de Colonias. 8-8-1939 Ley por la que se reorganiza la Administración del Estado, suprimiéndose la Viccpresidencia y asignando la Dirección 
General de Marruecos y Colonias al Ministerio de Asuntos Exteriores.

15-1-1942 Ley por la que la Dirección General de Marruecos y Colonias, afecta al Ministerio de Asuntos Exteriores, pasa a depender de la Presidencia del Gobierno.

21-8-1956 Decreto (Presidencia) por el que se crea la Dirección General de Plazas y Provincias Africanas.

\section{APFINDICE II}

Marco legislativo del Subgrupo de Fondos del Protectorado de España en Marruecos.

3-10-1904 Convenio hispano-francés sobre Derechos de España y Francia en Marruecos.

16-11-1910/12-1-1911 Acuerdo entre España y Marruecos.

"Art. 2". El Majcén confiará al Bajá del campo de Melilla, previsto por el art. $5^{\circ}$ del Convenio de 5 de Marzo de 1894 las funciones de alto comisario para concertarse con un alto comisario español...".

27-11-1912 Convenio entre España y Francia, celebrado el 27 de Noviembre de 1912, para precisar la situación respectiva de los dos países con relación al Imperio xerifiano.

"Las regiones comprendidas en la zona de influencia determinada en el art. $2^{\circ}$ continuarán bajo la autoridad civil y religiosa del Sultán en las condiciones del presente Acuerdo.

Dichas regiones serán administradas con la intervención de un alto comisario español, por un jalifa...

Los actos de la autoridad marroquí en la zona de influencia española serán intervenidos por el alto comisario español y sus agentes. El alto comisario será el único intermediario en las relaciones que el jalifa, en calidad de delegado de la autoridad imperial en la zona española, tendrá que mantener con los agentes oficiales extranjeros...".

27-2-1913 R. D. (P. del D. de M.) determinando cómo ha de realizarse el funcionamiento de la Acción española en Marruecos y unificando el mando en el Comandante General de Ceuta. 
Organización del embrión de Alta Comisaría: Un Delegado para los Servicios Indígenas, con, entre otras funciones, las relaciones con los agentes oficiales extranjeros; un Delegado para los Servicios de fomento de los intereses materiales; un Delegado para los Servicios Tributarios.

"Art. 1". Interín el canje de ratificaciones del Convenio hispano-francés permite organizar definitivamente el funcionamiento de la acción española en Marruecos, dependerán del comandante general de Ceuta todas las autoridades militares y consulares de España constituidos en su zona de influencia..."

"El comandante general de Ceuta se entenderá con el Gobierno y recibirá sus instrucciones por medio del Ministerio de Estado..."

"Art. 8'. Para cuantos asuntos de la zona de influencia española en Marruecos requieran el concurso de la Legación de S. M. en Tánger, el comandante general de Ceuta, el de Melilla y el de Larache se entenderán directamente con ella, siempre que la urgencia del caso lo exija, dando simultáneamente cuenta a la autoridad".

24-1-1916 R. D. (Estado) aprobando con carácter provisional el reglamento orgánico para la administración del Protectorado.

Organización: a) Un Residente General, Alto Comisario; b) Un Secretario General; c) Un Delegado de Asuntos Indígenas; d) Un Delegado para los Asuntos Tributarios, Económicos y Financieros; f) Los Cónsules; g) Los Interventores locales (que pueden ser los mismos Cónsules); h) La Intervención de Aduanas. Del Delegado de Asuntos Indígenas dependen la Inspección de Sanidad y la de Enseñanza.

"Art. 3. Del Alto Comisario dependerán las autoridades españolas de todos los órdenes constituidas en la zona con carácter permanente o temporal".

"Art. 5. El Alto Comisario será el único intermediario en las relaciones que el Jalifa y su Gobierno hayan de mantener con los agentes oficiales extranjeros".

"Arts. 16 a 19.- Los Cónsules... dependerán del Secretario General... ejercerán el derecho de protección... intervendrán en la resolución de reclamaciones extranjeras... y ejercerán además las 
funciones de intervención política y administrativa cerca de las autoridades locales".

"Art. 21. En las regiones donde exista Cónsul español será éste necesaria y exclusivamente el interventor local..."

11-5-1924 R. D.- Ley por el que se ensaya una acción del Protectorado preferentemente civil y se suprimen la "Inspección General de Intervención civil y Servicios Jalifianos" y la "Inspección general de Intervención Militar y tropas Jalifianas", creándose una "Sección Civil de Intervención" y una "Sección Militar de Intervención".

12-7-1924 R. D. (de la P. del G.) de Reglamento del Protectorado de España en Marruecos.

Organización: a) Un Residente General, Alto Comisario; b) Un Delegado General; c) Unos "Servicios de Intervención Givil y Asuntos Generales"; d) Unos "Servicios de Fomento de Intereses Materiales"; e) Unos "Servicios Tributarios, Económicos y Financieros".

2-10-1927 R. D.-Ley simplificando la Organización Militar de la Zona del Protectorado en Marruecos.

31-10-1927 R. D.-Ley (P. del C. de M.) atribuyendo la gobernación general de las plazas de soberanía española en el Norte de Africa al Alto Comisario.

“Art. 20. El Alto Comisario de España en Marruecos ejercerá el mando en dicha circunscripción administrativa y representará al Gobierno... con las facultades y atribuciones asignadas a los Gobernadores civiles..."

"Art. 3". El Alto Comisario ejercerá sobre las Juntas municipales de Ceuta y Melilla las funciones expresamente atribuidas a los Comandantes de Ceuta y Melilla por el Estatuto local de 14 de Febrero de 1927".

"Art. $6^{\circ}$. Para la tramitación de los asuntos de orden civil que se asignan al Alto Comisario, se organizará una Secretaría del Gobierno de las plazas y territorios de soberanía, adscrita a la Delegación General de la Alta Comisaría...".

10-4-1930 R. D. (P. del C. de M.) asignando al Alto Comisario funciones inspectoras sobre las autoridades y servicios de orden civil en Ceuta y Melilla y territorios de soberanía española. 
29-12-1931 Decreto (Presidencia) reorganizando los servicios de la Zona del Protectorado.

Organización: a) Alto Comisario; b) Jefe Superior de las Fuerzas Militares de Marruecos; c) Organos vinculados al Alto Comisario: Gabinete Militar y Gabinete Diplomático; d) Organos de la Alta Comisaría: Secretaría General, Delegación de Asuntos Indígenas, Delegación de Fomento, Delegación de Hacienda e Inspección de Intervenciones y Fuerzas Jalifianas.

19-7-1933 Decreto (P. del C. de M.) concediendo al Alto Comisario la autoridad de Gobernador Civil de Ceuta y Melilla.

18-12-1933 Decreto (P. del C. de M.) unificando y precisando las normas a que ha de ajustarse el nombramiento de Interventores jalifianos.

“a)... En las localidades en que existe un Consulado o Viceconsulado español de carrera, el titular del mismo ejercerá las funciones de Interventor local...".

15-2-1935 Decreto (P. del C. de M.) reorganizando los servicios del Protectorado.

Organización: a) Alto Comisario; b) Jefe Superior de las Fuerzas Militares de Marruecos; c) Organos vinculados al Alto Comisario: Secretaría Diplomática y Militar; d) Organos de la Alta Comisaría: Secretaría General, Delegado de Asuntos Indígenas, Delegado de Hacienda, Delegación de Fomento e Intervención de Servicios Marítimos.

8-11-1941 Ley introduciendo una nueva reorganización de los Servicios de la Alta Comisaría.

Organización: a) Alto Comisario; b) Organos vinculados directamente al Alto Comisario: Delegación de Asuntos Indígenas, Secretaría Diplomática, una Secretaría con tres Secciones (Asuntos relacionados con la acción del protectorado, Asuntos Militares y Asuntos de los territorios de Soberanía), la Subinspección de Fuerzas jalifianas, la Intervención de Marina; c) Organos superiores de la Administración del Protectorado: Secretaría general, Delegación de Asuntos Indígenas, Delegación de Educación y Cultura, Delegación de Economía, Industria y Comercio, Delegación de Obras Públicas y Delegación de Hacienda. 
“Art. 14... La Secretaría Administrativa comprenderá dos Secciones: la primera tendrá a su cargo el Registro General de entrada, salida y valijas, y la segunda, el Archivo. El Archivo comprenderá dos aspectos de la mayor importancia: el propio de la Secretaría General y el Archivo General Jalifiano... El Archivo Jalifiano se nutrirá de los Archivos de la propia Secretaría General y de las distintas Delegaciones, con arreglo a las instrucciones que se dicten, reuniendo así de un modo ordenado y metódico cuanto convenga sea archivado y permitiendo la utilización eficaz de esos archivos. Por la importancia que se da a esta función, estará al frente de la Secretaría Administrativa el Jefe de más categoría en la Zona del Cuerpo General Administrativo de la misma...

16-7-1945 Ordenanza reglamentando provisionalmente atribuciones del Delegado General y de los Delegados de Servicios.

"Art. $3^{\circ}$. Las misiones específicas del Delegado General... son las siguientes: ... b) Tener a su cargo los servicios de valija, excepto la diplomática, Registro General de entrada y salida de documentos y Archivo General del Protectorado.

23-9-1946 Decreto sobre funciones y competencia del Gobierno general de las Plazas de Soberanía.

"Art. $2^{\circ}$. A los efectos del artículo anterior, se vincula el cargo de Gobernador general de los territorios de Soberanía Española en Africa en el Alto Comisario de España en Marruecos, con facultades de ejercer desde cualquier lugar de los Territorios de Soberanía o del Protectorado la jurisdicción que le corresponden.

"Art. 7". Los servicios del Gobierno General... estarán a cargo de una Secretaría Técnica del Gobierno General...”.

\section{APNITDICW III}

Marco legislativo del Subgrupo de Fondos generado en relación la organización del Estatuto de Tánger.

27-11-1912 Art. $7^{\circ}$. del Convenio entre España y Francia, celebrado el 27 de Noviembre de 1912, para precisar la situación respectiva de los dos países con relación al imperio xerifiano. 
18-12-1923/7-2-1924 Convenio 18 Diciembre 1923-7 Febrero 1924, suscrito entre España, Francia e Inglaterra, relativo a la organización del expresado Estatuto.

“Arts. 29-30: S. M. Jerifiana designará para representarla en Tánger un Mendub que promulgará los textos legislativos votados por la Asamblea internacional con el visado, a los efectos de refrendo, del presidente del Comité de Control... El Comité de Control se compondrá de los Cónsules de carrera de las potencias Signatarias del Acta de Algeciras...".

"Art. 49. A partir de la vigencia del nuevo régimen, las agencias diplomáticas en Tánger serán reemplazadas por Consulados".

5-1-1933 Decreto (P. del C. de M.) Asignando la Acción de España en la Zona del Protectorado y en Tánger a la Presidencia del Consejo de Ministros.

"Art. 4". El Consulado general de España en Tánger, con todas funciones y servicios que el mismo tiene a su cargo, a excepción de lo que se refiere al régimen de su Cancillería consular, pasará a depender de la Presidencia del Consejo de Ministros.

Por este Departamento serán nombrados el Cónsul general y todos los demás funcionarios del Consulado...

Sin perjuicio de la dependencia del Cónsul General de España respecto a la $\mathrm{P}$. del C. de M. se considerará subordinado jerárquicamente al Alto Comisario de España en Marruecos, con el que podrá relacionarse directamente en aquellos asuntos que se determinen..."

5-11-1933 Decreto (P. del C. de M.) modificando el anterior de 5 de Enero, del que suprime, entre otros, el párrafo $3^{\circ}$ que acabamos de consignar.

9-11-1940 Decreto suprimiendo los órganos legislativos de la Zona de Tánger e incorporando ésta al Protectorado.

23-11-1940 Ley de Régimen Jurídico del Territorio de Tánger.

11-10-1945 Se restaura la vigencia del Estatuto de Tánger y se restablece la Zona.

16-11-1952 Revisión del Estatuto de Tánger a iniciativa española. 
1. Véanse en el Apéndice 1 el R. D. 18-1-1924 creando la Oficina de Marruecos en la Presidencia del Gobierno y la R.O. de fecha 4-1-1926 disponiendo el modo de llevarse las relaciones con los Gobiernos extranjeros e incluso_con el Servicio Exterior español por lo que respecta a la acción en la Zona del Protectorado y resto de las posesiones coloniales en $A$ frica.

2. "Rimarchevole, anche se poco nota, una definizione giustamente messa in rilievo da Papritz: quella data ai primi del nostro secolo, nelle sue lezioni, da Friedrich Küch, direttore dell'Archivio di Stato di Marburgo:

'Un archivio è la totalità dei residui scritti destinati a duratura conservazione, organicamente prodotti nella gestione degli affari o nel rapporto privato, di un'autorità, corporazione, famiglia o singola persona.

Vi si trovano i concetti di sedimentazione documtaria di un'attività amministrativa, di lotalità, di organicità dei documenti, e la nozione di archivio estesa anche alla doumentazione prodotta nei rapporti privati: una definizione ancor oggi perfettamente attuale"; (Elio Lodolini: Archivistica. Principi e problemi, Milán, Franco Angeli Editore, 1987). El subrayado es nuestro.

3. Los fondos de la Dirección de Marruecos y Colonias y de la Dirección de Plazas y Provincias Africanas fueron organizados en su día por funcionarios archiveros y de otros Cuerpos destinados en aquellos Centros Directivos. La del Grupo de Fondos del Protectorado constituyó una misión específica asignada a personal del Cuerpo de Archivos bajo la dirección de su lnspector Central, don Miguel Bordonau.

4. Cuestiones todas que, como el archivero sabe, han hallado un principio de respuesta, desde una perspectiva práctica, gracias a Michel Duchein (Vid. "Le respect des fonds en archivistique: Principes théoriques et problèmes pratiques", La Cazette des Archives, 1977).

5. El archivero acostumbra distinguir entre unidades archivísticas - como el fondo o la unidad documental-, cuya integridad es corolario de principios infrangibles, $y$ unidades de clasifi- cación, resultado de una operación que en algunos casos - tal la clasificación externa en Grupos de Fondos se efectúa desde fuera y pucde guiarse por criterios de utilidad con vistas a la difusión. (Vid. Louis Cardinual et alii: Les instruments de recherche pour les archives, La Pocatière, 1984, pp. 15-18).

6. Baste a comprobarlo la lectura del articulado correspondiente de las Disposiciones en que se crean o reorganizan las instituciones de intervención española en el Protectorado. Así, en el artículo 5 del R. D. 24-1-1916 por el que se reglamenta la administración del Protectorado "se fijan como funciones propias del Alto comisario: Velar por la recta observancia de los Tratados y ser el único intermediario en las relaciones con el Jalifa y su Gobierno hayan de mantener con los agentes oficiales extranjeros".

EI R. D. Ley de 11-V-1924 desde su mismo título anuncia que se ensaya una acción del Protectorado preferentemente civil; y en el artículo $1^{\circ}$ del "Decreto de 29-XII-1931 reorganizador de los servicios de la Zona", ha ocupado ya el primer plano como cometido principal del Alto Comisario "velar por el mantenimiento del orden en los territorios asignados a España $y$ prestar su asistencia al Majzén o Gobierno jalifiano".

7. Mencionemos asimismo la existencia en dicha Sección de documentación del Consulado en Tetuán de los años 1919 a 1969.

Para completar la lista de fuentes referentes a relaciones de España con el Norte de Africa, hay que tener en cuenta además que en el Archivo Central del Ministerio de Asuntos Exteriores se encuentra la correspondencia intercambiada por las Secciones competentes del Ministerio de Estado con la Legación en Tánger (1860-1925) y Consulados en Alcázarquivir (1911-1926), Arcila (1913-1929), Larache (1868-1930), Tánger (1850-1930) y Tetuán (1861-1930) (Vid. María Josefa Lozano Rincón y Enrique Romera Iruela: Guia del Archivo del Ministerio de Asuntos Exteriores, Madrid, Ministerio de Asuntos Exx1eriores. Secretaría General Técnica, 1981. 
8. Lo que desde el punto de vista administrativo no plantearía excesivos problemas, pues bastaría un acuerdo entre los Departamentos involucrados -Ministerio de Relaciones con las Cortes y Ministerio de Asuntos Exterioressobre a cuál de ambos competería la concesión de permisos de acceso para la totalidad del fondo.

9. Dado que en este trabajo hacemos uso de términos tales como el de inventario somero e inventario analítico, aclaremos que para nosotros existe una correlación bastante estrecha entre el cuadro de clasificación dotado de signa- turas que sirve de pórtico al inventario y el inventario mismo como los ha definido doña Antonia Heredia Herrera, y el inventario somero (répertoire sommaire) y el inventario (répertoire numérique simple), respectivamente, de las archivísticas canadiense o francesa, en este último caso con matizaciones. Pensamos también que el inventario analítico (répertoire numérique detaille) está contemplado en los escritos de la insigne tratadista, pese al rechazo por parte suya del térnino (Véase en este sentido el tratamiento que recomienda para las series misceláneas, pág. 257 de Archivistica General, Teoría y práctica). 


\section{San Juan de las Minas.}

noros de la harka amiga d

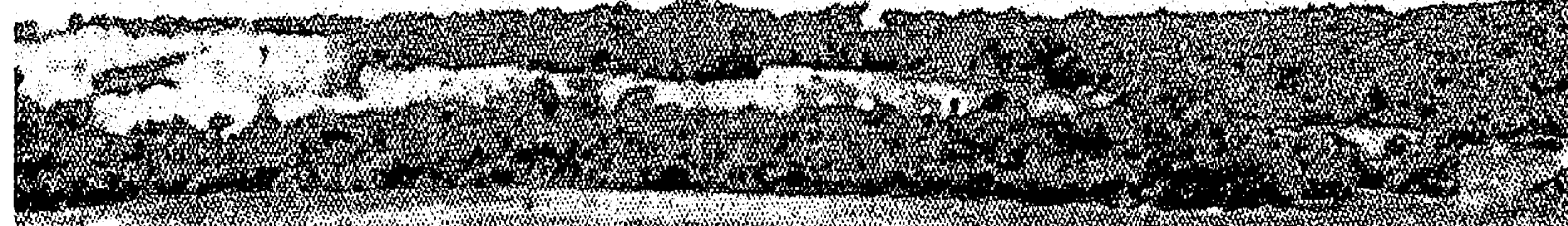

\$क

H)

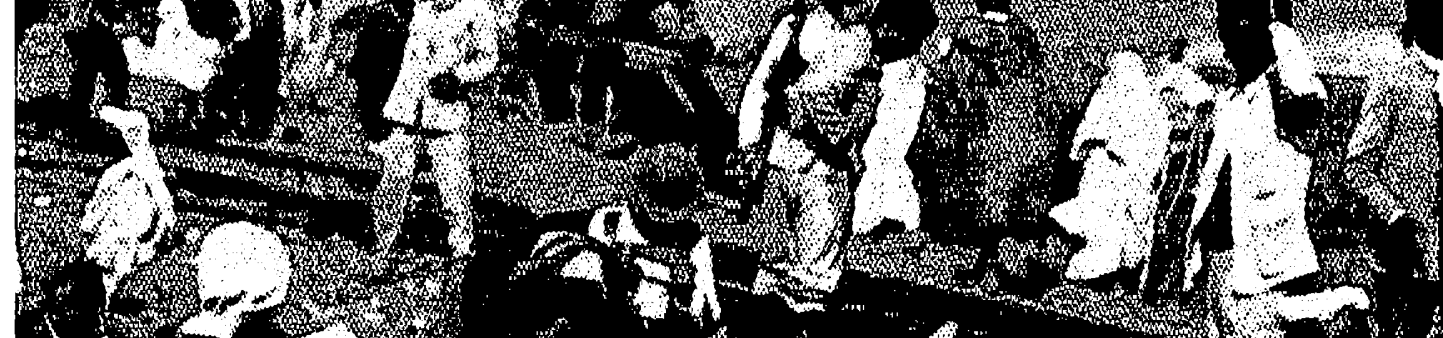

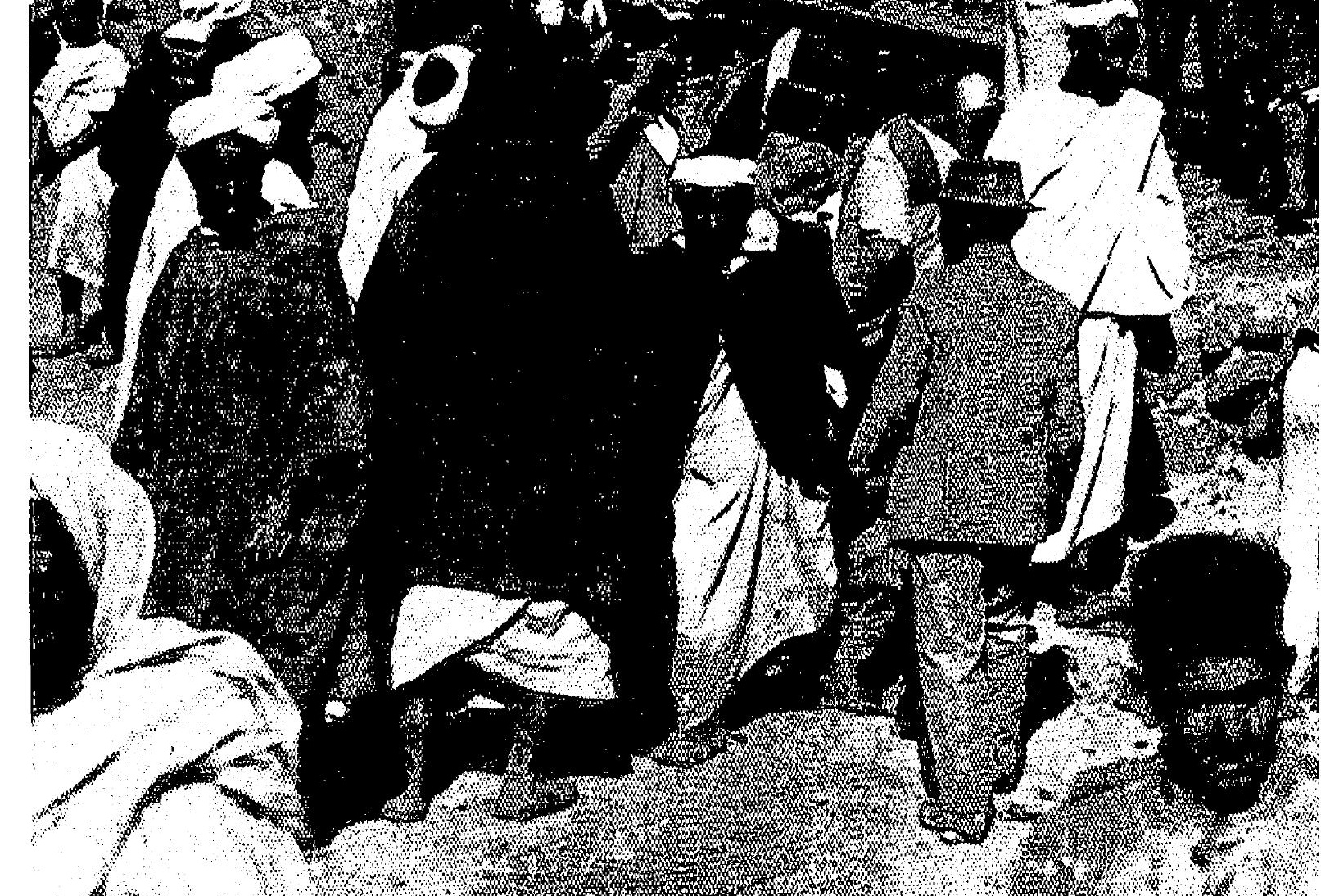

4. 
